\title{
TRABALHO NOS CENTROS DE ATENÇÃO PSICOSSOCIAL ÁLCOOL E DROGAS E AS POLÍTICAS PÚBLICAS: QUE CAMINHO SEGUIR?
}

\author{
WORKING AT PSYCHOSOCIAL ALCOHOL AND DRUG CARE CENTERS AND PUBLIC POLICIES: \\ WHICH IS THE WAY FORWARD?
}

TRABAJO EN LOS CENTROS DE ATENCIÓN PSICOSOCIAL ALCOHOL Y DROGAS Y LAS POLÍTICAS PÚBLICAS: ¿QUÉ CAMINO SEGUIR?

\author{
Kallen Dettmann Wandekoken ${ }^{1}$ \\ Maristela Dalbello-Araujo ${ }^{2}$
}

Resumo $\mathrm{O}$ artigo apresenta diferentes posicionamentos das políticas públicas brasileiras vigentes relacionadas ao uso de álcool e drogas e discute possíveis repercussões que tais divergências podem trazer para a atuação do trabalhador da área de saúde. Trata-se do resultado de pesquisa documental sobre essas políticas, tais como portarias, leis e decretos a partir de 1938 até aquelas vigentes atualmente. Optou-se por elencá-las de forma cronológica, considerando os dois principais posicionamentos políticos: 1 . foco na segurança pública e justiça; 2 . foco na saúde pública. Constatou-se que neste período houve uma clara tentativa de mudança de paradigma, de forma a abranger a prevenção ao uso e tratamento. No entanto, ainda se verifica nas políticas e, no senso comum, a presença de fortes traços de ideais de um mundo livre das drogas, a partir de conceitos moralistas, intolerantes e autoritários como da guerra às drogas, repressão e redução da oferta. É neste contexto que os profissionais da saúde pública, em especial aqueles que atuam nos centros de atenção psicossocial álcool e drogas, enfrentam o grande desafio e vivenciam efeitos subjetivos no cotidiano de atuação frente a tantas divergências e contradições.

Palavras-chave política; centros de atenção psicossocial; trabalhadores.
Abstract The article presents the different positions the current Brazilian public policies have on alcohol and drug abuse and discusses the possible effects such differences could have on the healthcare worker's performance. It is the outcome of documentary research on these policies, such as ordinances, laws, and decrees from 1938 to those currently in effect. We chose to list them chronologically, considering the two main political positions: 1 . Focus on public security and justice; 2 . focus on public health. We found that in this period there was a clear attempt to make a paradigm shift in order to include use prevention and treatment. However, the policies and the common sense still bear strong signs of idealistic views of a world free of drugs which are derived from moralistic, intolerant, and authoritarian concepts such as the war on drugs, repression, and reductions in supply. It is in this context that public health professionals, especially those working in psychosocial alcohol and drug abuse care centers, face the challenge and experience the subjective effects of everyday work at the face of so many differences and contradictions.

Keywords policy; psychosocial care centers; workers. 


\section{Introdução}

A temática de dependência química possui relevância na atualidade frente ao aumento do uso, abuso e dependência de substâncias psicoativas. A Organização Mundial de Saúde (OMS) destaca que cerca de $10 \%$ da população de centros urbanos de todo o mundo consome abusivamente substâncias psicoativas independentemente de idade, sexo ou nível de instrução (Brasil, 2004a). Dados do II Levantamento Domiciliar sobre o Uso de Drogas Psicotrópicas, realizado em 108 cidades brasileiras, revelam que 12,3\% da população brasileira é dependente de álcool e 10,1\% dependente de tabaco (Cebrid, 2006). E a temática está diretamente vinculada a questões sociais como a criminalidade, a prostituição, a situação de rua, o tráfico de drogas, a aids, entre outras (Kessler e Pechansky, 2008).

Assim, ao refletir sobre o uso, abuso e ou dependência de substâncias psicoativas, é preciso atentar para a complexidade da questão, considerando o indivíduo como ser único com necessidades e implicações biológicas, psicológicas, sociais, culturais e de desenvolvimento (Ribeiro, Sanchez e Nappo, 2010; Kessler e Pechansky, 2008).

Neste contexto, ressaltamos que há divergências entre as políticas atuais relacionadas ao uso de drogas, de forma que há aquelas mais próximas aos ideais de repressão e outras aos ideais da saúde pública e da redução de danos. Esta constatação torna a problemática ainda mais desafiadora para usuários, famílias e sociedade em geral, bem como para a consecução das políticas. Assim, para a atuação dos trabalhadores envolvidos, indaga-se: que caminho seguir? Até porque consideramos, com base em Merhy e Feuerwerker (2009), que os desejos, valores, crenças e interesses dos trabalhadores, e não só dos gestores, estão implicados na sua atuação no cotidiano. Assim, este artigo apresenta os diferentes posicionamentos das políticas públicas brasileiras vigentes, relacionadas ao uso de álcool e outras drogas, e discute possíveis repercussões que tais divergências percebidas possam trazer para a atuação do trabalhador da área de saúde neste contexto.

\section{Métodos}

Realizamos uma pesquisa documental ${ }^{3}$ das políticas destinadas ao enfrentamento do uso de álcool e outras drogas, a fim de vislumbrar os avanços e desafios frente à temática no país. Para Oliveira (2007), a análise documental constitui a busca de informações em documentos que não receberam nenhum tratamento analítico, ou seja, as fontes primárias. Considerando estas ideias, Sá-Silva, Almeida e Guindani (2009) mencionam que, ao utilizar documentos na coleta de dados, é preciso que estejamos aptos a avaliar sua 
credibilidade a partir de um olhar crítico. Além disso, os autores mencionam ser primordial que, em todas as etapas da análise documental, sejam avaliados o contexto histórico em que foram produzidos tais documentos, o contexto social e político do autor, bem como conhecer as questões socioeconômico-culturais e políticas que levaram à produção dos documentos.

Para tanto, nesta pesquisa, utilizamos documentos oficiais, como portarias, leis, decretos e políticas publicados no Diário Oficial da União. O recorte para a coleta foi o ano de 1938, ano em que o país passou a ter regulamentação sobre as drogas, até os dias atuais.

\section{Resultados e discussão}

A princípio, optamos por elencar os documentos de forma cronológica, analisando-os de modo crítico-reflexivo ao considerar os dois principais posicionamentos políticos relacionados à temática: 1. Políticas relacionadas ao uso indevido de drogas com foco na segurança pública e da justiça (relativo ao narcotráfico e à repressão da oferta); 2. Políticas relacionadas ao uso indevido de drogas com foco na saúde pública (relativo à repressão da demanda por um lado e à redução de danos por outro).

Verificamos que o país possui regulamentação sobre as drogas desde o ano de 1938, pelo decreto-lei de fiscalização de entorpecentes n. 891/38 (Brasil, 1938), incorporado ao artigo 281 do código penal em 1940 (Brasil, 1940), que expressa claramente o caráter proibicionista frente às drogas. Fato é que o Código Penal Brasileiro resulta de diversos aspectos focados na gestão de Getúlio Vargas (1930-1945) frente às preocupações com o comportamento desviante do trabalhador (Matos, 2000). Como exemplo, a autora destaca as campanhas contra o consumo de álcool que apresentavam o discurso normatizado de como o trabalhador deveria agir. Além disso, o Código evidenciava uma postura criminalizadora ao uso de drogas, independentemente da quantidade de droga apreendida e da distinção se era para uso próprio ou tráfico.

Nos anos seguintes, a Organização das Nações Unidas (ONU) realizou três convenções nos anos de 1961, 1971 e 1988 (Organização das Nações Unidas, 1961 ; 1971; 1988), conhecidas como as Convenções-Irmãs, expressas pela ideia war of drugs, o que também influenciou o Brasil nas determinações seguintes. Destacamos, assim, a lei n. 5.726 de 1971 que “dispõe sobre medidas preventivas e repressivas ao tráfico e uso de substâncias entorpecentes ou que determinem dependência física ou psíquica e dá outras providências" (Brasil, 1971). Nesta lei, são propostas várias medidas de prevenção e de repressão ao tráfico, de forma que o tratamento só é destinado aos infratores viciados que eram internados compulsoriamente, como mencionado no art. 10, do capítulo II. 
Art. 10. Quando o Juiz absolver o agente, reconhecendo que, em razão do vício, não possui este a capacidade de entender o caráter ilícito do fato ou de determinar-se de acordo com esse entendimento, ordenará sua internação em estabelecimento hospitalar para tratamento psiquiátrico pelo tempo necessário à sua recuperação (Brasil, 1971).

Como se vê, o enfoque da lei não está relacionado com a garantia do direito à saúde, e sim com a 'reabilitação do viciado'. Neste ponto é importante discutir a palavra vício, mencionada no art. 10 do capítulo II (Brasil, 1971). Ressaltamos que, hoje, sabe-se que a palavra tem origem no latim vitium e significa defeito, ofensa, imperfeição ou falta. Ou seja, a palavra expressa conotação pejorativa e está vinculada ao artigo da lei que se propõe a explicitar sobre o tratamento dos usuários de substâncias psicoativas.

Concordamos com Merhy e Feuerwerker (2009) quando afirmam que o trabalho em saúde está sujeito às ideias, valores e concepções do trabalhador, que utiliza de seus espaços de autonomia, mesmo que pequenos, para agir conforme seus valores e interesses. Ou seja, a forma como se entende o uso de substâncias psicoativas determina também a abordagem que será realizada. Há interesses, desejos, valores e crenças de gestores, bem como do coletivo de trabalhadores que atuam no cotidiano.

Destaca-se que no Brasil, até o ano de 1976, não havia uma legislação com foco sobre as questões relacionadas ao tratamento de usuários de substâncias psicoativas. As abordagens principais eram a repressão do tráfico e o controle do consumo de drogas, ou seja, as medidas eram restritas ao campo de segurança pública.

Zaluar (2007) menciona que o governo sempre adotou medidas de repressão frente à temática das drogas, de forma a proporcionar à polícia o poder de determinar quem será processado e preso como traficante - crime considerado hediondo 4 .

Em 1976, foi promulgada a lei n. 6.368 no governo militar de Ernesto Geisel (Brasil, 1976). Nesta lei, o foco passa a ser não apenas a prevenção ao tráfico, mas sim a prevenção do uso indevido de substâncias, como disposto no seu art. $4^{\circ}$ - ou seja, observam-se avanços em relação à lei de 1971 . Em relação ao tratamento, ressaltamos que a lei menciona a necessidade de que haja nos estados, territórios e distrito federal estabelecimentos próprios para o tratamento de dependentes de substâncias, 'sempre que necessário e possível' (Brasil, 1976). Portanto, a criação de serviços de tratamento não era uma determinação legal, mas apenas uma recomendação, demonstrando a importância secundária frente os ideais de repressão.

Além disso, a lei, em seu art. $10^{\circ}$, afirma que é obrigatório o tratamento sob regime de internação hospitalar quando a situação clínica do dependente se mostrar necessária e, ainda, enfatiza no $\S 1^{\circ}$ que "quando verificada a 
desnecessidade de internação, o dependente será submetido a tratamento em regime extra-hospitalar, com assistência do serviço" (Brasil, 1976).

Assim, constatamos que o texto da lei traz influências da concepção médica e psiquiátrica ao considerar o usuário um doente e ao instituir o hospital como dispositivo privilegiado da atenção.

No entanto, apesar de o art. 10 tratar sobre a questão médica, obervamos que as legislações sobre a temática das drogas, nessa época, eram focadas em ações baseadas na redução da oferta, com o objetivo de diminuir o consumo indevido de drogas pela dificuldade de acesso, de forma que se restringia ao campo jurídico. Além disso, o foco das intervenções era a repressão, ao buscar o controle do tráfico e do consumo de drogas a partir da penalidade da prisão tanto para o traficante quanto para o usuário (Brasil, 1976). Como se observa, em termos de punição, a lei não fazia nenhuma distinção entre traficante e usuário.

Nesse contexto, com base no decreto n. 85.110 de 1980, foi instituído o Sistema Nacional de Prevenção, Fiscalização e Repressão de Entorpecentes, que compreendia alguns órgãos, como o Conselho Federal de Entorpecentes (Confen) (Brasil, 1980). O Confen (e os demais conselhos de entorpecentes, sejam estaduais ou municipais) foi criado para atuar seguindo os ideais de abstinência e de repressão (Mesquita, 2004).

Já no ano de 1987, no Rio de Janeiro, ocorreu a I Conferência Nacional de

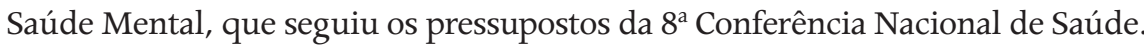
Assim, no documento final da conferência, reiterou-se a implementação da reforma sanitária e propôs-se a reformulação do modelo assistencial de saúde mental, além da reorganização dos serviços a fim de que o foco fosse serviços extra-hospitalares pela atuação das equipes multiprofissionais (Brasil, 1987).

Na Constituição promulgada em 1988, seu art. 227, § $3^{\circ}$ afirma ser dever do Estado instituir "programas de prevenção e atendimento especializado à criança e ao adolescente dependente de entorpecentes e drogas afins" e no art. 243, § único estabelece que "todo e qualquer bem de valor econômico apreendido em decorrência do tráfico ilícito de entorpecentes e drogas afins será confiscado e reverterá em benefício de instituições e pessoal especializados no tratamento e recuperação de viciados" (Brasil, 1988, p. 38). Além disso, a Constituição foca na repressão ao tráfico ao considerá-lo como crime inafiançável (art. 5 XLIII), na prevenção e repressão ao tráfico de produtos entorpecentes (art. 144) e na proibição do cultivo de plantas ilegais (art. 243) (Brasil, 1988).

Apesar do cenário de discussões e mudanças em que é promulgada, a Constituição ainda não trouxe elementos sobre a assistência aos usuários de drogas como um todo, uma vez que se refere apenas às crianças e adolescentes, e ao ressarcimento da verba das apreensões às instituições de tratamento. Nesse sentido, sabemos que, historicamente, os recursos rela- 
cionados à temática das drogas são mais direcionados à repressão em detrimento de atividades de prevenção e assistência, principalmente em relação às crianças e adolescentes.

Em 1989, passou a tramitar no Senado Federal o projeto de lei n. 3.657, conhecido como a 'lei antimanicomial' do deputado Paulo Delgado (Congresso Nacional, 1989). O projeto foi aprovado no Congresso em 1989, mas foram várias discussões e articulações políticas durante dez anos para que fosse aprovado no Senado, de forma que em 1995 foi aprovado nesta instância o Substitutivo de Lucídio Portella e rejeitou-se a lei antimanicomial. No início de 1999, o Substitutivo foi alterado com base em acordos frente ao projeto de Paulo Delgado e este é, então, aprovado no Senado, mas é regulamentado como lei somente em 2001 (Brasil, 2001a).

Antes da aprovação, a Organização Pan-Americana da Saúde (Opas) e a OMS divulgaram um documento, em 1990, intitulado: "A reestruturação da atenção psiquiátrica na América Latina: uma nova política para os serviços de Saúde Mental", conhecido como a Declaração de Caracas, que teve grande repercussão no país (Organização Pan-Americana da Saúde, 1990). Com este documento, a atenção psiquiátrica se vinculava à atenção primária em saúde, e os serviços comunitários passaram a ser a principal forma de se obter a prevenção, a partir de um atendimento participativo e contínuo.

No Brasil as mudanças se iniciaram em 1998, com algumas discussões da XX Assembleia Geral das Nações Unidas. O Confen foi transformado em Conselho Nacional Antidrogas (Conad) e foi criada uma secretaria, responsável pela criação da política pública relacionada ao uso de substâncias psicoativas, conhecida como Secretaria Nacional Antidrogas (Senad). A Senad era subordinada à área militar, ligada ao Gabinete de Segurança Institucional da Presidência da República, conforme a medida provisória n. 1.689 e o decreto n. 2.632 de 1998 (BRASIL, 1998a; 1998b). Em 2008 foi instituída a lei n. 11.754, alterando o nome do Senad para Secretaria Nacional de Políticas sobre Drogas e do Conad para Conselho Nacional sobre Drogas (Brasil, 2008).

Ressaltamos que, ainda em 1998, a ONU convocou uma Assembleia Geral, conhecida como UNGASS (Sessão Especial da Assembleia-Geral das Nações Unidas), a fim de discutir sobre a política mundial sobre drogas. Nesse evento, foram ratificadas as Convenções-Irmãs e estabeleceu-se o objetivo intitulado 'Um mundo livre de drogas: nós podemos fazê-lo' que deveria ser alcançado até 2008 (Organização das Nações Unidas, 1998).

Assim, constatamos que a criação da Senad foi uma iniciativa do governo, baseada em estratégia política, a fim de evidenciar a preocupação do país em relação ao combate às drogas para o meio internacional, principalmente em relação à pressão norte-americana. Entretanto, o 'lugar' que a Senad ocupa é polêmico desde a sua criação. Logo no início, a polícia federal questionava a função da secretaria e, assim, foram separadas as atribuições: a 
polícia, ligada ao Ministério da Justiça, era responsável pela repressão ao tráfico, e a Senad se responsabilizava pelas ações preventivas (Brasil, 2001b).

Desde sua criação, as mudanças na Senad têm sido estimadas e nunca concretizadas. Um exemplo disso é a proposta de vinculação da Senad ao Ministério da Justiça (Dantas e Constantino, 2003). Essa questão foi solucionada no governo Dilma, em 2011, quando a Senad, até então chefiada pelo general Paulo Roberto Uchôa, passou a ser chefiada por um civil, no Ministério da Justiça, com base no decreto n. 7.426 (Brasil, 201 la).

No entanto, o que se observa hoje é uma série de discussões em relação a essa mudança. Seria adequada? Houve, de fato, alguma mudança? Concordamos que a transferência da secretaria para a coordenação do Ministério da Justiça trouxe avanços a partir do fortalecimento de suas ações, mas concordamos também com Laranjeira, Carlini e Marques (2003, p. 1) quando mencionam que essa transferência não é interessante, visto que não se deve articular uma secretaria com função de prevenção a um órgão forte e corporativo como a polícia federal. Esta, segundo os autores, é a forma mais "simples de destruir o caráter social e comunitário da nossa política antidrogas. Teremos aí sim uma política militarizada e repressora como os críticos da política americana temem".

Além disso, ressaltamos que o papel do Ministério da Justiça é relacionado com combate às drogas, repressão do tráfico, entrada das drogas no país, entre outras questões afins à temática de segurança pública. Constatamos que a questão do uso de substâncias psicoativas no país é muitas vezes tida como um 'caso de polícia' e não de saúde, e nos questionamos sobre a abordagem biopsicossocial do uso de substâncias psicoativas, uma vez que a questão social relacionada às drogas, por exemplo, é ainda um grave problema. Acreditamos que o foco no quesito repressão não é suficiente, devendo haver uma abordagem mais ampla, relacionada à prevenção, ao tratamento, à reinserção social e à redução de danos. Logo, o Ministério da Saúde e o Ministério do Desenvolvimento Social devem participar ativamente deste processo de forma integrada, para não correr o risco de fragmentação.

Retomando à análise histórica, frente às discussões iniciadas em $1998 \mathrm{e}$ a partir do projeto de lei de Paulo Delgado, no ano de 2001, foi promulgada a lei n. 10.216 que ratificou de forma histórica as diretrizes básicas que constituem o Sistema Único de Saúde (SUS), tornando-se um marco legal da reforma psiquiátrica no país. Para tanto, a lei garante aos usuários de serviços de saúde mental, bem como aos usuários de substâncias psicoativas, a universalidade de acesso, o direito à assistência, a integralidade, a descentralização dos serviços, além de configurar a rede de forma atenta às desigualdades existentes (Brasil, 2001a). Com isso, a torna-se o instrumento normativo máximo para a Política de Atenção aos Usuários de Álcool e outras Drogas (Paiuad) - que será discutida adiante. 
Em 2002, a Senad coordena a articulação entre governo e sociedade e, por meio do decreto n. 4.345, institui a Política Nacional Antidrogas (Pnad). Nesse sentido, a Pnad foi elaborada pela Senad, pelo Departamento da Polícia Federal e por outros agentes do Sistema Nacional Antidrogas (Sisnad) com objetivos e diretrizes relacionados à redução da oferta e da demanda de drogas e vinculados à prevenção, tratamento, recuperação, reinserção social, redução de danos, repressão, estudos, pesquisas e avaliações (Brasil, 2002a).

A existência da Pnad ampliou os debates em relação à temática das drogas, sendo necessário realinhar os fundamentos da Pnad frente às transformações que ocorriam no país e no mundo. A Política Nacional Antidrogas foi criada ainda no governo de Fernando Henrique Cardoso, com foco no uso de drogas e não no indivíduo, e só foi modificada em 2004, no governo Lula, para Política Nacional sobre Drogas pela Senad após a realização de vários debates e fóruns com a participação da comunidade civil e científica, aprovada por meio da resolução n. 3/ GSIPR/CONAD no ano de 2005 (Brasil, 2005).

No entanto, mesmo após as alterações na política, é importante discutir alguns pressupostos. No primeiro pressuposto afirma-se que se deve "buscar, incessantemente, atingir o ideal de construção de uma sociedade protegida do uso de drogas ilícitas e do uso indevido de drogas lícitas", retratando o uso de drogas como uma ameaça à vida da sociedade (Brasil, 2002a, p.1).

Ao discutir este pressuposto, há duas questões a serem analisadas. A primeira se refere à busca por uma sociedade livre do uso de drogas ilícitas, do que discordamos por ser uma ideia utópica; e a segunda diz respeito à busca por uma sociedade livre do uso indevido de drogas lícitas, do que também discordamos. Há grande perpetuação de propagandas e mídias que enfatizam o uso dessas substâncias em atividades cotidianas e festivas, além do vasto domínio das indústrias de bebidas, tabaco, entre outras que lucram diante do consumo demasiado de tais substâncias.

Assim, constatamos um descompasso entre a realidade e a Pnad, perante o desafio atual da regulamentação do uso indevido de drogas e da cultura aceitável do consumo de drogas lícitas, até porque sabemos que o álcool e o tabaco são responsáveis por grande parte dos problemas advindos do uso de substâncias psicoativas.

Outro pressuposto relevante é a diferenciação que a política aponta entre o traficante de drogas, o usuário, a pessoa em uso indevido e o dependente, de forma que reconhece que deve haver diferenciações e aponta que estes também devem ter tratamento igualitário, sem discriminação. Todavia, no pressuposto seguinte, menciona que a sociedade deve ser conscientizada de que "o uso de drogas ilícitas alimenta as atividades e organizações criminosas" (Brasil, 2002, p. 1). Neste ponto, é clara a necessidade de tais diferenciações, uma vez que as abordagens devem divergir das especificidades 
de cada caso. No entanto, é complexa a associação entre os pressupostos, visto que a política em questão se pauta na repressão e na criminalização do uso de drogas ilícitas, ou seja, expõe uma ideia moralista à opção pelo uso de drogas ilícitas ao vincular o uso destas à criminalidade. Assim, é difícil vislumbrar o tratamento igualitário e sem discriminação a esses sujeitos.

Além disso, é preciso analisar com mais detalhes este último pressuposto: “buscar a conscientização do usuário e da sociedade em geral de que o uso de drogas ilícitas alimenta as atividades e organizações criminosas que têm, no narcotráfico, sua principal fonte de recursos financeiros" (Brasil, 2002a, p. 1). Neste ponto devemos atentar para o fato de que, em certa medida, o pressuposto considera o usuário responsável pelas atividades de tráfico, de forma que é importante nos questionarmos se, e em que proporção, outros atores apresentam menor importância.

Ressaltamos, ainda, mais um pressuposto: "não confundir as estratégias de redução de danos como incentivo ao uso indevido de drogas, pois se trata de uma estratégia de prevenção" (Brasil, 2002a, p. 2). Enfatizamos mais uma vez que uma política que se propõe a defender a ideia de redução de danos não está de acordo com a ideia de repressão e criminalização do uso de drogas ilícitas, como visto nos parágrafos anteriores. Não fica clara a concepção que a política se propõe a defender quanto ao pressuposto relacionado à redução de danos. Deste modo, constatamos que há na política dois modelos distintos para abordagem à temática, que podem ser explicados por conflitos de interesse e divergências entre os representantes de ambas abordagens, seja a repressão ou a redução de danos.

Além dos pressupostos, a Pnad baseia-se em cinco eixos: l. Prevenção; 2. Tratamento, recuperação e reinserção social; 3. Redução dos danos sociais e à saúde; 4. Redução da oferta; 5. Estudos, pesquisas e avaliações (Brasil, 2002a). A Pnad vinculada à Senad traz alguns avanços nessas questões ao considerar esses cinco eixos que avançam na redução do enfoque repressivo expresso em órgãos governamentais anteriores como o Confen e o Conad. Apesar dos avanços, há grandes desafios, uma vez que a Senad era subordinada ao Gabinete de Segurança Institucional da Presidência da República. Assim, cabe-nos um questionamento: esses ideais ainda proibicionistas observados na Pnad impedirão o avanço da discussão no âmbito da saúde pública? A repressão como estratégia principal contra a problemática, além de estar associada à violência, valoriza o enfrentamento do uso indevido de drogas ilícitas em detrimento do uso de drogas lícitas - que apresenta efeitos tão ou mais devastadores. Dessa forma, consideramos que seja uma ideia simplista abordar a questão com foco na repressão, sendo imprescindível a abordagem no âmbito biopsicossocial. A esta discussão acrescentamos que a própria Constituição Federal evidencia os direitos e garantias fundamentais a todos os cidadãos, o que não é observado nos ideais proibicionistas. 
Em 2003, concomitantemente à Política Nacional Sobre Drogas - elaborada pela Senad, vinculada ao Gabinete de Segurança Institucional -, o Ministério da Saúde instituiu a já mencionada Política de Atenção Integral ao Usuário de Álcool e Drogas - Paiuad (Brasil, 2004a) por meio da portaria n. 2.197/GM (Brasil, 2004b), com princípios e diretrizes que apontam em direção contrária à Pnad - como discutiremos a seguir.

A princípio, devemos considerar que a Paiuad foi construída, no governo Lula, com base na reivindicação de usuários, familiares e trabalhadores por um tratamento mais digno, o que lhe confere um caráter contra-hegemônico, em consonância com a III Conferência de Saúde Mental (Brasil, 2002b), a lei n. 10216/2001 (Brasil, 2001a) e os pressupostos da OMS. Assim, apesar de a temática de enfrentamento do uso de álcool e outras drogas ter sido considerada um assunto de saúde pública tardiamente, hoje, encontram-se na Paiuad as principais diretrizes. Até porque a Paiuad tem como eixo norteador os princípios do SUS e da Reforma Psiquiátrica. Ou seja, com a política afirma-se a responsabilidade do SUS na atenção à temática do álcool e outras drogas, questão que até então era contemplada, de forma predominante, por instituições não governamentais, como comunidades terapêuticas, e grupos de mútua-ajuda.

As legislações do Ministério da Saúde que embasam as orientações da política são: Portaria GM 336/2002, que estabelece os CAPS I, CAPS II, CAPS III, CAPS i II e CAPS ad II (Brasil, 2002c); Portaria SAS 189/2002, que regulamenta a portaria 336 e estabelece a criação do Centro de Atenção Psicossocial Álcool e Drogas no SUS (Brasil, 2002d); Portaria GM 816/2002, que institui o Programa Nacional de Atenção Comunitária Integrada aos Usuários de Álcool e outras Drogas (Brasil, 2002e).

Constatamos, assim, que a criação da Paiuad foi fortemente baseada nas discussões sobre as mudanças do modelo de atenção em saúde, contra os ideais repressivos e proibicionistas relacionados ao enfrentamento do uso indevido de álcool e outras drogas. Neste sentido, há algumas divergências entre a Paiuad e a Pnad. A princípio, é possível notar que a linguagem utilizada na Paiuad não condiz com concepções moralistas ou repressivas da Pnad. Neste contexto, destacamos um trecho da Paiuad (Brasil, 2004a, p. 26):

[...] de forma a impactar positivamente na redução do consumo de drogas, no resgate do usuário do ponto de vista da saúde e não tão somente moralista ou legalista, e em estratégias de comunicação que reforçam o senso comum de que todo consumidor é marginal e perigoso para a sociedade.

Além disso, a Paiuad foca na redução dos danos em suas diretrizes, em detrimento da redução da oferta - divergindo da Pnad. As estratégias de redução de danos elencadas na Paiuad não se restringem a ações como a troca 
de seringas ou de cachimbos, mas se referem a ações relacionadas à diminuição dos danos em vários aspectos. Ou seja, as ações não são focadas no controle da epidemia da aids, mas nas possibilidades de prevenção e de assistência.

Para tanto, a lógica da redução de danos, posta na política, possibilita aos usuários escolhas, considerando-os enquanto sujeitos-cidadãos e não excluindo a abstinência, e ainda enfatiza que "há necessidade de mudança no paradigma de 'doentes' para novos cidadãos merecedores de direitos e exercício pleno da cidadania" (Brasil, 2004a, p. 30).

Ao enfatizar que a temática é complexa e que o uso de álcool e outras drogas é um grave problema de saúde pública, a política propõe que os direitos dos cidadãos sejam atendidos de forma igualitária e que se busque a autonomia das pessoas. É, portanto, contrária à ideia de abstinência total como objetivo único a ser alcançado e enfatiza a proposta de redução de danos a fim de que os usuários sejam acolhidos em suas diferenças, considerando sua singularidade e sempre estimulando sua participação e engajamento. Assim a política oferece a redução de danos como método e, dessa forma, não exclui outros (Brasil, 2004a).

Outra diferença que constatamos é que a questão das drogas passa a ser entendida como aspecto humano, e que a ideia de repressão baseada na segurança pública não é mais considerada eficaz. Ou seja, a questão passou a ser enfrentada como sendo da saúde pública ao focar aspectos como a prevenção, o tratamento, a redução de danos e a reinserção social. Assim, entre os objetivos da política, destacamos: "desconstruir o senso comum de que todo usuário de droga é um doente que requer internação, prisão ou absolvição" (Brasil, 2004a, p. 24).

Desta forma, acreditamos que a ideia de redução de danos posta na Paiuad traz aspectos da integralidade em relação ao cuidado das pessoas que usam drogas. Até porque, a partir da redução de danos, o usuário é considerado alguém com interesses, dificuldades e desejos além do uso de drogas. Ou seja, o uso da droga é apenas um aspecto, de modo que o papel dos profissionais não deve ter como foco o uso da droga e, sim, o sujeito, sua singularidade.

Além disso, a política ressalta que a problemática possui implicações sociais, psicológicas, econômicas e políticas e necessidade de fortalecimento de uma rede de atenção centrada na atenção comunitária. Dessa forma, possibilita a atenção integral e implanta os serviços de atenção comunitária a esses usuários, conhecidos como os Centros de Atenção Psicossocial Álcool e Drogas (CAPS ad), proporcionando o acesso facilitado ao usuário e o tratamento multiprofissional, ao articular ações de redução de danos, prevenção, recuperação, tratamento e reinserção social (Brasil, 2004a). Para tanto, a política reconhece que a problemática das drogas é um desafio da saúde pública e procura envolver a sociedade no debate, na formulação e no 
acompanhamento de respostas às demandas nesta área. A implantação desses serviços está de acordo com as diretrizes da reforma psiquiátrica, que propõe a substituição do modelo hospitalocêntrico por dispositivos extra-hospitalares. Nesse contexto, são vários os objetivos de um CAPS ad, como a prestação de atendimento diário seguindo a lógica da redução de danos; a promoção da reinserção social; o cuidado com os familiares; a busca pela diminuição do estigma e preconceito quanto ao uso de substâncias psicoativas (Brasil, 2004a, p. 34).

Outra questão é que, na Paiuad, o consumo de álcool é considerado um grave problema de saúde pública e enfatiza-se a necessidade de uma política pública relativa ao uso dessa substância - concretizada somente em 2007, em consequência dos avanços nas discussões das políticas nacionais relacionadas ao uso de substâncias psicoativas. Neste sentido, em 2007, a Senad elaborou a nova Política Nacional sobre o Álcool, com base no decreto n. 6.117 de 2007 (Brasil, 2007), e consagrou a importância da abordagem ao alcoolismo como um problema de saúde pública nacional.

Antes disso, em 2006, foi promulgada a lei n. 11.343, considerando a necessidade de revogação da lei n. 6.368/76 e da lei n. 10.409/2002, e regulamentada pelo decreto n. 5.912 (Brasil, 2006). Verificamos alguns avanços com a promulgação desta lei. Apesar de ainda acentuar a ideia de repressão à produção não autorizada de drogas e ao tráfico ilícito, com aumento das penalidades, a lei distingue a condição de usuários e traficante. Desta forma, o usuário de droga não é mais julgado como traficante na vara criminal comum, e passa a ser julgado na justiça restaurativa com a possibilidade de reflexão e de reinserção social. Ou seja, embora o uso não tenha sido descriminalizado, a lei enfatiza atividades de prevenção ao uso indevido, como a atenção à saúde e a reinserção social do usuário. O indivíduo identificado com porte de drogas para uso pessoal deve ter acesso a oportunidades de reflexão, em detrimento do encarceramento, e aplicadas medidas socioeducativas pelos juizados especiais criminais.

No entanto, apesar dessas constatações, cabem algumas reflexões. Em que medida o Estado deve penalizar o uso de drogas? Em que medida deve se posicionar contra ou a favor do uso ou porte de uma substância psicoativa? Não caberia ao próprio indivíduo esta escolha?

Concordamos que as atuais políticas e o senso comum possuem uma visão muito mais repressora e estigmatizadora em relação ao uso de drogas do que a busca pela proteção dos indivíduos em sua singularidade. Há sim, como menciona Wollmann (2009), uma invasão da liberdade individual, com foco na repressão e na criminalização, de forma que a prevenção esteja associada com a persecução criminal e com interesses que vão contra a democracia.

Ainda, nesta discussão, é importante destacar um avanço com a promulgação da lei, que prevê o fim do tratamento obrigatório para dependentes 
de drogas. $\mathrm{O}$ art. $28, \S 7^{\circ}$ afirma que deverá ser colocado à disposição do sujeito, gratuitamente, o tratamento especializado em serviço de saúde, de preferência ambulatorial (Brasil, 2006). Isto é um avanço tardio, uma vez que o sujeito já não era obrigado ao tratamento das demais doenças. Então, em que medida o Estado deveria obrigar o tratamento ao indivíduo que faz uso ou porte de drogas?

É possível constatar uma clara associação entre uso de drogas e doença nas políticas e no senso comum. Visão que se busca desconstruir desde a promulgação da Paiuad, ao afirmar que não é adequada a ideia de que "todo usuário é um doente que requer internação, prisão ou absolvição" (Brasil, 2003). Mas há, ainda, uma confusão entre o que seria a dependência química, o uso de drogas recreativo e o uso indevido e abusivo. Questões que implicam a 'demonização' do uso de drogas (e do usuário).

Continuando o percurso histórico, com o aumento do número de usuários de crack, o Ministério da Saúde, em consonância com a Paiuad, elaborou em 2009 o Plano Emergencial de Ampliação do Acesso ao Tratamento e à Prevenção em Álcool e outras Drogas (Pead). Entre as finalidades do Pead está "ampliar o acesso ao tratamento e à prevenção em álcool e outras drogas no SUS" (Brasil, 2009).

Sobre a questão do estigma, o Pead reitera que deve haver o enfrentamento do estigma social, uma vez que há ainda grandes barreiras devido à compreensão de que só devem ser ofertadas políticas repressivas aos usuários. Já sobre a adoção da estratégia de redução de danos, o plano destaca que este deve ser um norte de qualquer serviço do SUS, e não somente dos serviços relacionados à saúde (Brasil, 2009).

No mesmo ano, foi lançado o Plano de Enfrentamento ao Crack e outras Drogas, com vistas à prevenção do uso, ao tratamento e à reinserção social de usuários e ao enfrentamento do tráfico do crack e outras drogas ilícitas. As ações deste plano incluem a intersetorialidade, a interdisciplinaridade, a integralidade, a participação da sociedade e o controle social. Além disso, afirma-se que o plano está em consonância com a Política Nacional sobre Drogas (Brasil, 2009).

Um ano após, em 2010, o governo criou o Plano de integração das ações voltadas para a prevenção, tratamento e reinserção social de usuários de crack e outras drogas (Brasil, 2010a; 2011b) e a Campanha Nacional de Alerta e Prevenção ao Uso de Crack (Brasil, 2010b) sob a afirmação de que 'O crack causa dependência e mata!', do Ministério da Saúde. E, no ano seguinte, dando continuidade a essas ações, o governo lançou o Programa 'Crack: é possível vencer!', em ação conjunta nas áreas de saúde, segurança, assistência social, educação e direitos humanos, a partir de três eixos de atuação: prevenção, cuidado e autoridade (Brasil, 2011c). Ressaltamos, ainda, a campanha do Conselho Nacional de Justiça (CNJ), lançada em 2011, 
que veicula um discurso de terrorificação do uso do crack expressa no slogan 'crack, nem pensar' (Conselho Nacional de Justiça, 2013), e o que antes era a atenção ao álcool e outras drogas passa ser crack, álcool e outras drogas - conferindo status a esta substância.

Frente a isto, a mídia aumenta a repercussão de combate ao crack, veiculando informações de aumento acelerado do uso da substância no país e de associação com o aumento da violência. Embora seja destacada a epidemia do uso de crack, o último levantamento do Centro Brasileiro de Informações sobre Drogas (Cebrid), realizado em 2005, aponta a droga como na $11^{a}$ colocação entre as drogas ilícitas, em relação ao uso na vida. Ou seja, sem considerar o uso de substâncias como o álcool e o tabaco, o uso do crack foi identificado em 0,7\% da população brasileira (Centro Brasileiro de Informações Sobre Drogas Psicoativas,, 2006). Outra pesquisa, realizada pela Fundação Oswaldo Cruz (Fiocruz), em 2013, constatou que 0,8\% da população brasileira consumia crack e/ou similares de forma regular (Fiocruz, 2013). Ou seja, em sete anos praticamente não houve aumento no consumo da droga que justifique o alarme quanto a uma suposta epidemia.

Não cabe nesta análise a discussão sobre os aspectos destrutivos do crack, uma vez que seria optar pelo mesmo caminho expresso na política e nas campanhas. O que buscamos ressaltar é o pânico que se promove em relação a uma substância ao exigir medidas duras de repressão. A guerra às drogas aponta essa substância como uma ameaça para a vida social, de forma que as premissas que justificam essas ações estão baseadas na necessidade de maior produtividade no trabalho ou de vínculos familiares. Ou seja, aponta para afirmações de como a vida deve ser vivida, e não na liberdade de escolha, no que deveria ser o direito de ir e vir de todos os cidadãos.

Concomitante a essas questões, em 2011, o Ministério da Saúde, com base na lei n. 10.216/2001 e nas diretrizes da Paiuad, instituiu a "Rede de Atenção Psicossocial para pessoas com sofrimento ou transtorno mental e com necessidades decorrentes do uso de crack, álcool e outras drogas, no âmbito do SUS" (Brasil, 2011d). A portaria tem como uma de suas finalidades a articulação de uma rede de atenção psicossocial frente a esta temática. Além disso, considera o respeito aos direitos humanos e a autonomia das pessoas, foca na redução de danos e busca combater os estigmas e preconceitos.

\section{Considerações finais}

Atualmente há dois posicionamentos políticos para o enfrentamento do uso indevido de drogas; por um lado, as políticas proibicionistas por meio da redução da oferta com foco na repressão do tráfico e do uso de drogas, e, por 
outro, as políticas focadas na redução de danos que visam diminuir os riscos do uso de drogas, sem enfatizar a proibição do uso.

Diante disso, no contexto atual, vemos a tentativa de mudanças de paradigmas, de forma que, em vez da guerra às drogas, repressão e redução da oferta, haja prevalência da prevenção, tratamento e dos direitos humanos. No entanto, ainda prevalece, na política ou no senso comum, os ideais de um mundo livre das drogas, a partir de ideais moralistas, intolerantes e autoritários.

Vários foram os avanços nas políticas públicas brasileiras quanto ao uso de drogas, como a compreensão de que a problemática deve ser entendida como uma questão de saúde pública e não somente a partir do âmbito da segurança pública e da justiça. No entanto, ainda há muito que ser feito e há aspectos teóricos que precisam ser assimilados na prática cotidiana dos serviços. Desta forma, compreendemos que há um tempo entre a publicação de diretrizes e sua assimilação pelos dirigentes, mas é imprescindível que isso aconteça de modo intersetorial, uma vez que os ideais da Paiuad precisam ter aplicabilidade prática. De nada adianta a promulgação de políticas, leis e decretos se não ocorrerem mudanças no cotidiano dos serviços. É nesse contexto que os trabalhadores dos CAPS ad têm um grande desafio e de fato vivenciam efeitos subjetivos no cotidiano de atuação frente a tantas divergências e contradições.

Além disso, é preciso lembrar que há pessoas envolvidas, desejos e singularidades no debate sobre as políticas. Assim, por mais que as políticas devam generalizar ao normatizar, é preciso que considerem as experiências subjetivas. Caso contrário, os aspectos humanos serão reduzidos às normas. É preciso que as políticas atentem para a diversidade e é imperioso que sejam analisados a forma e os efeitos que tais contradições e discrepâncias trazem para o cotidiano de trabalho dos profissionais socialmente encarregados de atuar nessas ações e corporificar essas políticas. Nesse sentido, está em andamento um estudo para verificar como os trabalhadores de um CAPS ad vivenciam os efeitos subjetivos do processo de trabalho (Wandekoken, 2013). 
Resumen El artículo presenta diferentes posiciones de las políticas públicas brasileñas vigentes relacionadas con el uso de alcohol y drogas, y discute las posibles repercusiones que tales divergencias pueden conllevar para la actuación del trabajador de la salud. Se trata del resultado de investigación documental sobre estas políticas tales como ordenanzas, leyes y decretos, a partir de 1938, hasta las actualmente vigentes. Se optó por presentarlas en forma cronológica, cosiderando dos posiciones políticas principales: 1 . foco en la seguridad pública y la justicia; 2 . foco en la salud pública. Se constató que en ese período hubo una clara intención de cambio de paradigma, con el fin de abarcar la prevención del uso y el tratamiento. Sin embargo, todavía se observa en las políticas y en el sentido común, la presencia de fuertes rasgos de ideales de un mundo libre de drogas, a partir de conceptos moralistas, intolerantes y autoritarios como de la guerra a las drogas, represión y reducción de la oferta. Es en este contexto que los profesionales de la salud pública, especialmente aquellos que trabajan en los centros de atención psicosocial de alcohol y drogas, enfrentan el gran desafío y vivencian efectos subjetivos en la actuación cotidiana frente a tantas divergencias y contradicciones.

Palabras clave política; centros de atención psicosocial; trabajadores.

\section{Notas}

1 Programa de Pós-Graduação em Saúde Coletiva da Universidade Federal do Espírito Santo, Vila Velha, Espírito Santo, Brasil.

$<$ kallendw@gmail.com>

Correspondência: Avenida Antonio Gil Veloso, n. 702, Praia da Costa, CEP 29101-010, Vila Velha, Espírito Santo, Brasil.

2 Programa de Pós-Graduação em Saúde Coletiva, Universidade Federal do Espírito Santo, Vila Velha, Espírito Santo, Brasil.

$<$ dalbello.araujo@gmail.com>

3 Esta pesquisa, que faz parte da tese de doutorado de um dos autores, foi aprovada pelo Comitê de Ética em Pesquisa da Universidade Federal do Espírito Santo e financiada pela Coordenação de Aperfeiçoamento de Pessoal de Nível Superior (Capes).

Não houve qualquer tipo de conflito de interesses.

4 Crime hediondo é aquele considerado pelo Poder Legislativo como o que merece maior reprovação pelo Estado e está previsto na lei n. 8.072 de 1990 (Brasil, 1990), promulgada no Governo Collor em resposta à violência. 


\section{Referências}

BRASIL. Casa Civil. Subchefia para assuntos jurídicos. Decreto-lei n. 891, de 15 de novembro de 1938. Diário Oficial da União. Brasília: 1938.

BRASIL. Casa Civil. Subchefia para assuntos jurídicos. Decreto-lei n. 2.848, de 7 de dezembro de 1940. Código Penal. Diário Oficial da União. Brasília: 1940.

BRASIL. Casa Civil. Subchefia para assuntos jurídicos. Lei n. 5.726, de 29 de outubro de 1971. Dispõe sobre medidas preventivas e repressivas ao tráfico e uso de substâncias entorpecentes ou que determinem dependência física ou psíquica. Diário Oficial da União. Brasília: 1971.

BRASIL. Lei n. 6.368, de 21 de outubro de 1976. Dispõe sobre medidas de prevenção e repressão ao tráfico ilícito e uso indevido de substâncias entorpecentes ou que determinem dependência física ou psíquica. Diário Oficial da União. Brasília: 1976.

BRASIL. Decreto n. 85.110, de 02 de setembro de 1980. Institui o Sistema Nacional de Prevenção, Fiscalização e Repressão de Entorpecentes e dá outras providências. Diário Oficial da União. Brasília: 1980.

BRASIL. Ministério da Saúde. Divisão Nacional de Saúde Mental. Relatório Final da I Conferência Nacional de Saúde Mental. Rio de Janeiro, 1987.

BRASIL. Casa Civil. Subchefia para assuntos jurídicos. Constituição da República Federativa do Brasil de 1988. Diário Oficial da União. Brasília: 1988.

BRASIL. Lei n. 8.072, de 25 de julho de 1990. Dispõe sobre os crimes hediondos e determina outras providências. Diário Oficial da União. Brasília: 1990.

BRASIL. Casa Civil. Subchefia para assuntos jurídicos. Medida provisória n. 1.689, de 19 de junho de 1998. Altera a lei n. 9.649, de 27 de maio de 1998 que dispõe sobre a organização da Presidência da República e dos Ministérios. Diário Oficial da União. Brasília: 1998a.

BRASIL. Subchefia para assuntos jurídicos. Decreto n. 2.632, de 19 de junho de 1998. Dispõe sobre o Sistema Nacional Antidrogas. Diário Oficial da União. Brasília: 1998b.

BRASIL. Lei n. 10216 de 6 de abril de 2001. Dispõe sobre a proteção e os direitos das pessoas portadoras de transtornos mentais e redireciona o modelo assistencial em saúde mental. Diário Oficial da União. Brasília: 2001a.

BRASIL. Decreto n. 3.845 de 13 de junho de 2001. Aprova a Estrutura do Gabinete de Segurança Institucional da Presidência da República, na parte referente à organização da Secretaria Nacional Antidrogas, o seu Quadro Resumo de Custos dos Cargos em Comissão e das Funções Gratificadas, e dá outras providências. Diário Oficial da União. Brasília: 2001b.

BRASIL. Decreto n. 4.345 de 26 de agosto de 2002. Institui a Política Nacional Antidrogas. Diário Oficial da União. Brasília: 2002a.

BRASIL. Sistema Único de Saúde. Conselho Nacional de Saúde. Ministério da Saúde. Relatório da III Conferência Nacional de Saúde Mental: cuidar sim, excluir não. Brasília: 2002b. 213p.

BRASIL. Ministério da Saúde. Portaria n. 336/GM, de 19 de fevereiro de 2002. Estabelece CAPS I, CAPS II, CAPS III, CAPS i II e CAPS ad II. Diário Oficial da União. Brasília: 2002c.

BRASIL. Ministério da Saúde. Portaria SAS n. 189, de 20 de março de 2002. Regulamenta a portaria n. 336 e estabelece a criação do Centro de Atenção Psicossocial Álcool e Drogas no Sistema Único de Saúde. Diário Oficial da União. Brasília: 2002d. 
BRASIL. Ministério da Saúde. Portaria n 816/GM, de 30 de abril de 2002. Institui, no âmbito do Sistema Único de Saúde, o Programa Nacional de Atenção Comunitária Integrada aos Usuários de Álcool e outras Drogas. Diário Oficial da União. Brasília: 2002e.

BRASIL. Ministério da Saúde. A política do Ministério da Saúde para atenção integral a usuários de álcool e outras drogas. Brasília: Ministério da Saúde, 2004a.

BRASIL. Portaria n. 2197/GM, de 14 de outubro de 2004. Redefine e amplia a atenção integral para usuários de álcool e outras drogas, no âmbito do Sistema Único de Saúde. Diário Oficial da União. Brasília: 2004b.

BRASIL. Resolução n. 3/ GSIPR/CONAD, de 27 de outubro de 2005. Aprova a Política Nacional sobre Drogas. Diário Oficial da União. Brasília: 2005.

BRASIL. Casa Civil. Subchefia para assuntos jurídicos. Lei n. 11343, de 23 de agosto de 2006. Diário Oficial da União. Brasília: 2006.

BRASIL. Casa Civil. Subchefia para assuntos jurídicos. Decreto n. 6117, de 22 de maio de 2007. Diário Oficial da União. Brasília: 2007.

BRASIL. Casa Civil. Subchefia para assuntos jurídicos. Lei n. 11754, de 23 de julho de 2008. Diário Oficial da União. Brasília: 2008.

BRASIL. Ministério da Saúde. Portaria n. 1.190, de 4 de junho de 2009. Institui o Plano Emergencial de Ampliação do Acesso ao Tratamento e Prevenção em Álcool e outras Drogas no Sistema Único de Saúde SUS (Pead 2009-2010) e define suas diretrizes gerais, ações e metas. Diário Oficial da União. Brasília: 2009.

BRASIL. Casa Civil. Subchefia para assuntos jurídicos. Decreto n. 7.179, de 20 de maio de 2010. Institui o Plano Integrado de Enfrentamento ao Crack e outras Drogas. Diário Oficial da União. Brasília: 2010a.
BRASIL. Campanha Nacional de Alerta e Prevenção ao uso do Crack. 2010b. Disponível em: <http://youtube.com/watch?v= 8m2_57-KUeM>. Acesso em: 28 jan. 2014.

BRASIL. Casa Civil. Subchefia para assuntos jurídicos. Decreto n. 7.426, de 7 de janeiro de 2011. Diário Oficial da União. Brasília: 2011a.

BRASIL. Casa Civil. Subchefia para assuntos jurídicos. Decreto n. 7.637, de 8 de dezembro de 2011. Diário Oficial da União. Brasília: 2011b.

BRASIL. Governo Federal. Programa 'Crack: é possível vencer!'. Brasília: 2011c.

BRASIL. Portaria n. 3.088, de 23 de dezembro de 2011. Institui a Rede de Atenção Psicossocial no SUS- RAPS. Diário Oficial da União. Brasília: $2011 \mathrm{~d}$.

CENTRO BRASILEIRO DE INFORMAÇÕES SOBRE DROGAS PSICOATIVAS. (CEBRID). II Levantamento domiciliar sobre o uso de drogas psicotrópicas no Brasil: estudo envolvendo as 108 maiores cidades do país 2005. São Paulo: Cebrid/Unifesp, 2006.

CONGRESSO NACIONAL. Projeto de lei n. 3.657/89, de 27 de setembro de 1989. Dispõe sobre a extinção progressiva dos manicômios. Diário Oficial da União. Brasília, 1989.

CONSELHO NACIONAL DE JUSTIÇA (CNJ). Crack, nem pensar. 2013. Disponível em: $<$ www.cnj.jus.br/campanhas-page/14856crack-nem-pensar $>$. Acesso em: 30 jan. 2014.

DANTAS, I.; CONSTANTINO, L. Lula decide manter Senad com militares. Folha de São Paulo, 2003. Disponível em: <www1. folha.uol.com.br/fsp/cotidian/ff2907200316. htm>. Acesso em: 29 nov. 2013.

FUNDAÇÃO OSWALDO CRUZ (Fiocruz). Ministério da Saúde. Secretaria Nacional de Políticas sobre Drogas. Ministério da Justiça. Estimativa do número de usuários de crack e/ou similares nas capitais do país. 2013. 
Disponível em: <www.casacivil.gov.br/ noticias/estimativa-capitais.pdf $>$. Acesso em: 30 jan. 2014.

KESSLER, F.; PECHANSKY, F. Uma visão psiquiátrica sobre o fenômeno do crack na atualidade. Revista de Psiquiatria do Rio Grande do Sul, Porto Alegre, v. 30, n. 2, p. 1-3, 2008.

LARANJEIRA, R.; CARLINI, E.; MARQUES, A. C. Em defesa da politica nacional antidrogas. Unidade de pesquisas em álcool e drogas, 2003. Disponível em: <uniad.org.br>. Acesso em: 16 jan. 2014.

MATOS, M. I. S. Meu lar é o botequim. São Paulo: Nacional, 2000.

MERHY, E. E.; FEUERWERKER, L. C. M. Novo olhar sobre as tecnologias de saúde: uma necessidade contemporânea. In: MANDARINO, A. C. S.; GOMBERG, E. (Org.). Leituras de novas tecnologias e saúde. Bahia: Editora UFS, 2009. p. 29-56.

MESQUITA, F. Politicas públicas de drogas: a construção de um caminho democrático e humanitário para o Brasil. 2004. Disponível em: $<$ www.reduc.org. br/pages.php?recid $=4>$. Acesso em: 10 maio 2014.

OLIVEIRA, M. M. Como fazer pesquisa qualitativa. Petrópolis: Vozes, 2007.

ORGANIZAÇÃO DAS NAÇÕES UNIDAS (ONU). Single convention on narcotic drugs. New York: 1961. Disponível em: <www. unodc.org/pdf/convention_1961_en.pdf $>$. Acesso em: 14 maio 2014.

ORGANIZAÇÃO DAS NAÇÕES UNIDAS (ONU). Convention on psychtropic substances. Viena: 1971. Disponível em: <www. unodc.org/pdf/convention_1971_en.pdf $>$. Acesso em: 14 maio 2014.

ORGANIZAÇÃO DAS NAÇÕES UNIDAS (ONU). Convención de Las Naciones Unidas Contra el Tráfico Ilícito de Estupefacientes y Substancias Sicotrópicas. Viena: 1988. Disponível em: <www.unodc.org/pdf/convention_ 1988_es.pdf>. Acesso em: 14 maio 2014.
ORGANIZAÇÃO DAS NAÇÕES UNIDAS (ONU). General Assembly: declaration. 1998. Disponível em: <www.un.org/documents/ ga/res/20sp/a20spr02.htm>. Acesso em: 29 jan. 2014.

ORGANIZAÇÃO PAN-AMERICANA DA SAÚDE (OPAS). Organização Mundial de Saúde. Declaração de Caracas. Caracas, 1990.

RIBEIRO, L. A.; SANCHEZ, Z. M.; NAPPO, S. A. Estratégias desenvolvidas por usuários de crack para lidar com os riscos decorrentes do consumo de droga. Jornal Brasileiro de Psiquiatria, Rio de Janeiro, v. 59, n. 3, 2010.

SÁ-SILVA, J. R.; ALMEIDA, C. D.; GUINDANI, J. F. Pesquisa documental: pistas teóricas e metodológicas. Revista Brasileira de História \& Ciências Sociais, São Leopoldo, ano 1, n. 1, 2009.

ZALUAR, Alba. Drogas: um panorama no Brasil e no mundo. Instituto de Medicina Social, Universidade do Estado do Rio de Janeiro, 2007. Disponível em: <www.drogas. org.br/portaldrogas/Artigo.asp?IdArtigo= 209>. Acesso em: 26 nov. 203.

WANDEKOKEN, Kallen. D. Efeitos subjetivos do processo de trabalho vivenciados por trabalhadores que atuam em um Centro de Atenção Psicossocial Álcool e Drogas. 2013. 92 f. Tese (Doutorado em Saúde Coletiva) Programa de Pós-graduação em Saúde Coletiva, Universidade Federal do Espírito Santo, Espírito Santo, 2013.

WOLLMANN, A. M. Drogas, violência, criminalização ao uso de psicoativos e os direitos humanos: contribuições para um debate necessário. Revista Eletrônica de Ciências Sociais, Minas Gerais, v. 8, p. 46-75, 2009.

Recebido em 19/05/2014

Aprovado em 18/05/2015 